\title{
Tradition and Innovation in the Cariri region of Ceará: the use of handicrafts in the shoe manufacturing process in the UFCA Product Design Department.
}

\author{
Juliana Loss Justo1, Saymo Venicio Sales Luna2 \\ ${ }^{1}$ Federal University of Cariri, Professor of the Department of Product Design at the Interdisciplinary Institute of Society, Culture and Art, \\ Crato-CE-Brazil \\ ${ }^{2}$ Federal University of Cariri, Postgraduate in Social Innovation in Solidarity Economy of the Center for Applied Social Sciences, Crato- \\ CE-Brazil
}

\begin{abstract}
This work presents the results of the project "Materials and Process of Footwear Manufacturing: Tradition and Innovation", developed in the Department of Product Design of the Federal University of Cariri. Through a report from the point of view of the teacher/coordinator of the discipline and an artisan/entrepreneur, also part of the project, we sought to present the development of the project activities, as well as highlighting the positive and negative points of the experiences. The project combined the academic knowledge of the discipline with traditional handicrafts of the region. The gains from the practice were several for both sides involved.
\end{abstract}

Keywords: Footwear sector, handicrafts, university extension.

\section{The Footwear Sector, Handicrafts and the University in Cariri}

The region of Cariri in the State of Ceará (Cariri cearense), stands out in the scenario of the national footwear sector making it third in the ranking of regions that produce footwear. In addition, it sets itself up as the largest producer of Ethyl-Vinyl-Acetate (EVA) rubber sheets, a component widely used in local production. (AMARAL FILHO, SOUZA, 2003)

Beserra (2009) divides the sector into three groups, the first being made up of handicraft units, which carry traditional references preserving their cultural characteristics, using leather as the main component. According to the author, this group develops its activities in small spaces in its residences or in city centers, where production and commercialization occur simultaneously. The second is the small and medium-sized factories focused on production and processing of synthetic materials, aimed primarily at the female audience. Finally the third group, "Grendene, a company isolated from the historical context of Cariri, which arrived in Cariri through the programs of industrial attraction." (BESERRA, 2009, p.96)

${ }^{a}$ Corresponding author: juliana.loss@ufca.edu.br
Currently, the sector is in decline, in view of the invasion of low price Chinese products, in addition to the economic situation of the country. It is worth noting that the profile of local production does not have a uniqueness in design, which further weakens the sector.

The region still stands out for having a vast cultural wealth, through its popular arts and handcrafted practices of the most diverse types such as braids, wood sculptures and leather artifacts. However, several artisans and/or productive groups are finding it difficult to enter the market, which is becoming more competitive every day.

In Ceará the handicraft sector receives support through private institutions and public policies for the promotion, training and commercialization of handicraft products. According to the Department for Labor and Social Development - STDS - the Ceará Craft Center has about 42 thousand registered artisans. These professionals are mostly organized in associations of craftsmen, artists or farmers, in which the marketing of products serves as a complement or main source of family income.

However, an expressive number of groups is still disregarded by government programs, making evident the need for participation of other institutions to assist the sector. 
It should be noted that the Cariri region is recognized for its natural beauties located in the semi-arid region of the Northeast, more precisely in the extreme south of the state of Ceará. It is home to the Araripe National Forest, the country's first national forest, as well as numerous springs and an extensive aquifer that supplies the municipalities of the region. The advance of industries, the uncontrolled urban growth, and "backyard industries" (among these footwear) have contributed to the degradation of these natural resources.

In this context, the Federal University of Cariri (UFCA) was created in 2013 from the breakup of the Federal University of Ceará. Its function is to act as a transforming agent in the region being made up of ten undergraduate departments among these, the department of Product Design with qualifications in jewelry and footwear. It is the function of the academy, its faculty and design students, to observe, understand, and act on the transformation of the problems described earlier.

One of the activities developed within the department that sought to combine the current situation of the footwear sector together with crafts was the project "Materials and Process of Footwear Manufacturing: Tradition and Innovation" held over two semesters in 2016. This paper seeks to report the development of the project, as well as results achieved and difficulties encountered.

It should be clear that this text was written by two people describing our experience participating in the project as teacher of the discipline and artisan /entrepreneur.

\section{The project "Materials and Process of Footwear Manufacturing: Tradition and Innovation"}

Understanding the challenges presented above, we were able to align them to a new modality of projects proposed in partnership between the Division of Continuing Education and Teaching and the Project of Interaction, Teaching and Continuing Education - PEEX. With the purpose of encouraging continuing education actions through disciplines, the modality offered the ideal opportunity to create a dialogue and exchange knowledge between university and the local community. This modality was created to contemplate the disciplines of several courses, generally practical, that already carried out activities of extension.

The project was designed to approach the discipline of Materials and Processes for the Manufacture of Footwear to local producers, be they industries or artisans. The classes took place once a week with a duration of 4 hours and had 9 students enrolled. The project proposed the following steps: the mapping of artisans and industries, the realization of workshops on handicraft techniques, the realization of shoe workshops, and the realization of an exhibition with the results.
Parallel to this, print materials were produced geared towards both academic and external audiences.

The mapping of the artisans took place in partnership with the Program for the Creative Economy "DO CARIRI", which aims at enhancing the socioeconomic development of Cariri's creative entrepreneurs through their identification, networking and strengthening, and fostering of the creative economy of the region. The program is based on the principles of cultural diversity, sustainability, social inclusion and innovation. Thus, the project could count on a mobilized public and a well established market.

From the mapping of interested artisans and creative entrepreneurs, we held meetings to plan the workshops that would be given by them to the students of the discipline and other interested parties. Throughout the first half of the year, workshops were carried out in weaving, screen printing and free embroidery. Here we will more specifically address the results achieved in the weaving technique.

The third phase needed to be adjusted in format. Instead of workshops, the students developed their shoes in partnership with the craftsmen and the workshop was given by the university shoe-lab technician, since we realized the need for technical modeling, a skill not yet developed with the students.

The print material consisted of a portfolio explaining the project experience during the first semester and presenting results. This portfolio is still in finalization phase.

It is noteworthy that the Division of Continuing Education held at UFCA is well established and follows the guidelines proposed by the Forum for Public Institutions of Brazilian Higher Education Divisions FORPROEX (2013) which are: Dialogic Interaction, Interdisciplinarity and Interprofessionality, Indissociability Teaching-Research-Continuing Education, Impact on Student Training, and Social Transformation. So, for the construction of the project, we also take these guidelines into consideration.

Another important aspect was the dialogue between design and crafts. When design approaches craft practices, which in Brazil dates back to the 1980s (BORGES, 2011), it is possible to observe some gains in relation to sustainability. The importance of traditional practices, the importance of collaborative organizations and creative communities are some aspects that, according to Manzini (2008), the designer must understand and value so that his or her work is indeed sustainable.

\subsection{Experience from the artisan point of view}

From the invitation to participate in the project through the "DO CARIRI" Program we sought to plan an activity relating weaving technique to the composition of footwear. 
At first, a weaving workshop was developed for students, teachers and technicians involved in the project. We briefly discussed the history of weaving, types of looms and raw materials. Next, we experimented with a manual loom (Figure 1). The students were encouraged to weave using several non conventional materials in the technique, highlighting the possibility of the use of alternative materials aiming for a greater sustainability of the pieces. In a collaborative way, we composed a fabric and then discussed the theme thus removing any doubts that arose along the way.

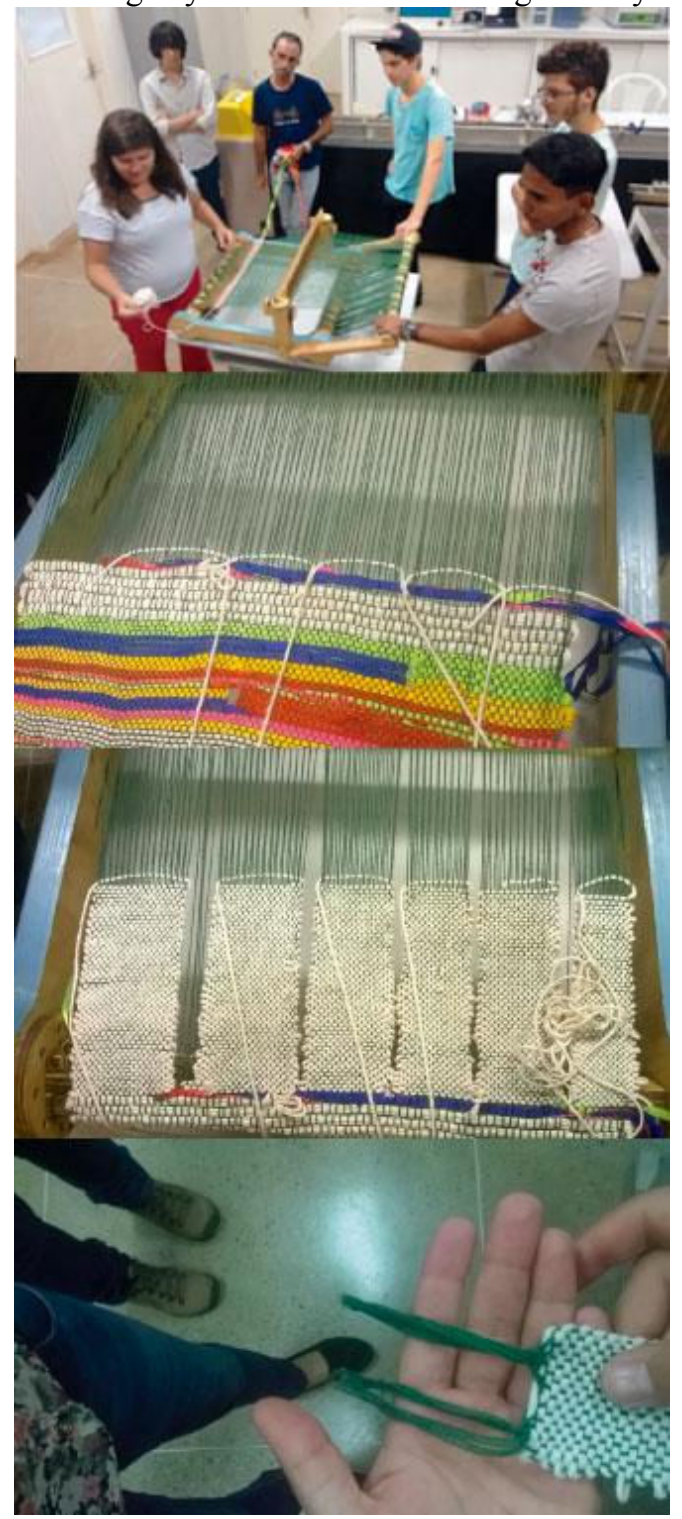

Figure 1. Experimentation in weaving workshop.

Source. Authors

In a second phase, we participated in a training with a technician in footwear of the university, where basic information was shared on modeling of shoes and the making of molds. Parallel to this training, we developed, with the students, collections of shoes using the technique experienced during the project, resulting in a physical prototype. During the creation process, we had encounters for experimentation, in which we defined the raw materials, the modeling, and finishes that would be used in the composition of each piece.

Two collections were developed. In the first, banana fiber and the cotton thread would be used as raw materials for the composition of the "cabedal" (the part of the shoe above the sole) and EVA sole. The second collection used only woven cotton yarn to build the "cabedal" parts and EVA sole.

The project revealed the possibility of the dialogue between academics and the external community, offering an exchange of knowledge that created new possibilities for application of the techniques, consequently increasing the flow of sales. Enabling the students to practice techniques in the field, contributed to an intellectual and professional enrichment, brought them closer to the local community, and certainly serve as an advantage when in the professional world.

On the other hand, we noticed a short period for the development of the activities, limiting the trials and tests.

\subsection{The experience from the teacher's point of view}

Carrying out the project was both enriching and challenging. On the one hand, the contact with creative entrepreneurs and learning their techniques, undoubtedly gave a great uniqueness to the discipline. On the other hand, coordinating external community, academics, and other teachers and disciplines requires attention and care with regards to the specificities and pace of each one.

One of the fears was that the craft workshops would "steal" discipline time, which didn't happen. The acquired knowledge went beyond that of the course description and, in a way, filled a gap in the university the lack of equipment for shoe construction, making the craft process an alternative to that of the industrial. It was a creative solution that promoted innovation.

The weaving technique also allowed for the presentation and discussion of typical footwear processes, such as "viras"- a type of fold finish along the cabedal edge or welt - and add-ons - inserts made for assembling, making seams and other finishes.

The final work of the students reached a satisfactory result, and everyone was able to insert the techniques learned in their collections. 


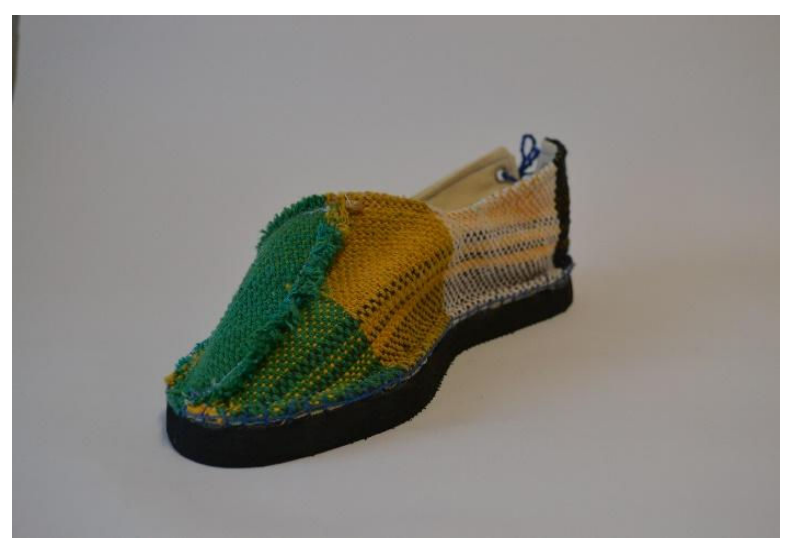

Figure 2. Shoe developed in partnership between.

Source. Authors

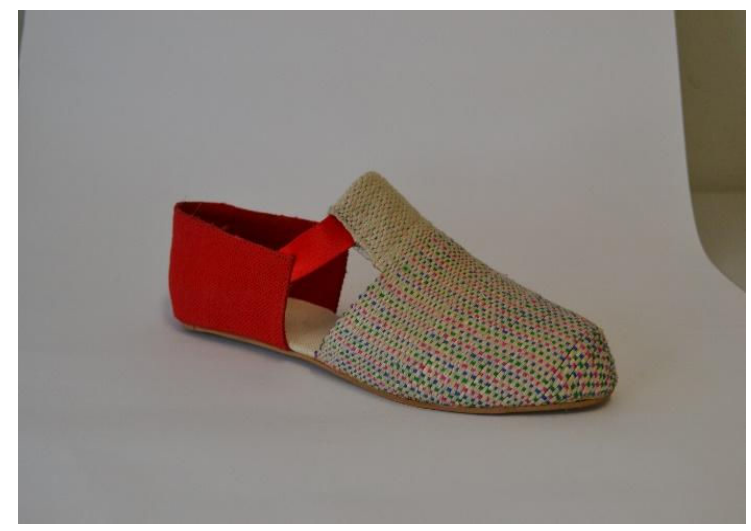

Figure 3. Shoe developed in partnership between

Source. Authors

This in fact provided a uniqueness to the projects and opened up a dialogue with local culture, one of the pillars of sustainability (SACHS, 2002).

\section{Final considerations}

The "Materials and Process for Shoe Manufacturing: Tradition and Innovation" project initiated a rich dialogue between shoe design and local handicrafts. For the students, the experience allowed for the development of products that were more appropriate to their context, since approach with the industry remains a challenge and is still not consolidated. Student Sieudo told us that a projectless participation allowed him to become familiar with various materials and techniques available in the region to use in his projects.

Regarding the involvement of the industrial sector, we were unable to establish partnerships beyond technical visits which demonstrated no interest in participating in a project of this kind. We believe that they are more interested in individual consulting activities.
One of the great results we sought in this project was the insertion of a new product in the "mix" of participating artisans and creative entrepreneurs. Due to technical limitations of suppliers and equipment, this result has not yet been achieved. The short period of work together interfered in this process, as well as the difficulty of conciliating schedules, as mentioned before. Therefore, it can be said that there is still a deficit with the external aspect of the project.

It is important to note that in second semester of 2016 the project was paused because the coordinator was on maternity leave, which also compromised the timetable.

The project, in agreement with teachers and artisans, will continue in 2017 , which allows us to broaden the participation of the public, in addition to strengthening the project's fragilities. The work will be carried out on two fronts: one in the identification of new participants, to offer more workshops, and the other in the improvement and development of footwear with the craftsmen involved since the beginning of the project. We believe the challenge will be to develop, in partnership, products that require the least possible equipment and specific tools, such as presses and molds.

It is noteworthy that there was a breakthrough in the sustainability of the products when, for example, banana fiber - from banana-growing residues - was used in the composition of the "cabedals". However, it is also noticeable the need for greater investments in research and development of components such as handmade and sustainable soles.

We also believe that this case can serve as an experience to replicate the proposal in other disciplines, making the UFCA Product Design Department increasingly accessible to the outside community.

\section{References}

AMARAL FILHO, J. do; SOUZA, D. L. R de. Arranjo produtivo de calçados do Cariri, Ceará. Fortaleza: SEPLAN/IPECE, 2003. 22p.

BESERRA, F. R. S. Reestruturação do Capital e Indústria Calçadista na Região do Cariri- CE. R. RA'E GA, Curitiba, n. 18, p. 89-101, 2009. Editora UFPR94

BORGES, A. Design + artesanato: o caminho brasileiro. São Paulo: Editora Terceiro Nome. 2011.

FORPROEX. Política Nacional de Extensão Universitária. Recife: UFPE, 2013.

MANZINI, E. Design para a inovação social e sustentabilidade. Cadernos do Grupo de Altos Estudos, Programa de Engenharia de Produção da Coppe/UFRJ, Rio de Janeiro, v. 1, 2008.

SACHS, I. Caminhos para o desenvolvimento sustentável. Rio de Janeiro: Garamond, 2002. 